\title{
Arterial Stiffness in Nonhypertensive Type 2 Diabetes Patients in Ghana
}

\author{
Kwame Yeboah, ${ }^{1}$ Daniel A. Antwi, ${ }^{1}$ and Ben Gyan ${ }^{2}$ \\ ${ }^{1}$ Department of Physiology, School of Allied \& Biomedical Sciences, University of Ghana, Accra, Ghana \\ ${ }^{2}$ Department of Immunology, Noguchi Memorial Institute for Medical Research, University of Ghana, Legon, Ghana
}

Correspondence should be addressed to Kwame Yeboah; melvinky@gmail.com

Received 7 April 2016; Revised 31 May 2016; Accepted 26 June 2016

Academic Editor: Mario Maggi

Copyright (C) 2016 Kwame Yeboah et al. This is an open access article distributed under the Creative Commons Attribution License, which permits unrestricted use, distribution, and reproduction in any medium, provided the original work is properly cited.

Background. Increased arterial stiffness is an independent cardiovascular risk factor in diabetes patients and general population. However, the contribution of diabetes to arterial stiffness is often masked by coexistent obesity and hypertension. In this study, we assessed arterial stiffness in nonhypertensive, nonobese type 2 diabetes (T2DM) patients in Ghana. Methods. In case-control design, 166 nonhypertensive, nonobese participants, comprising 96 T2DM patients and 70 nondiabetes controls, were recruited. Peripheral and central blood pressure (BP) indices were measured, and arterial stiffness was assessed as aortic pulse wave velocity (PWVao), augmentation index (AIx), cardioankle vascular index (CAVI), and heart-ankle pulse wave velocity (haPWV). Results. With similar peripheral and central BP indices, T2DM patients had higher PWVao $(8.3 \pm 1$ versus $7.8 \pm 1.3, p=0.044)$ and CAVI $(7.9 \pm 1.2$ versus $6.9 \pm 0.7, p=0.021)$ than nondiabetic control. AIx and haPWV were similar between T2DM and nondiabetic controls. Multiple regression models showed that, in the entire study participants, the major determinants of PWVao were diabetes status, age, gender, systolic $\mathrm{BP}$, and previous smoking status $(\beta=0.22,0.36,0.48,0.21$, and 0.25 , resp.; all $p<0.05)$; the determinants of CAVI were diabetes status, age, $\mathrm{BMI}$, heart rate, $\mathrm{HbAlc}$, total cholesterol, $\mathrm{HDL}$ cholesterol, and previous smoking status $(\beta=$ $0.21,0.38,0.2,0.18,0.24 .0 .2,-0.19$, and 0.2 , resp.; all $p<0.05)$. Conclusion. Our findings suggest that nonhypertensive, nonobese T2DM patients have increased arterial stiffness without appreciable increase in peripheral and central pressure indices.

\section{Introduction}

Type 2 diabetes (T2DM) is a major risk factor for the development of cardiovascular diseases (CVDs) [1]. It is estimated that, in the next 20 years, sub-Saharan Africa will have the highest growth in the number of people with diabetes among all other regions of the world, and this will increase the CVD burden $[2,3]$. Traditional risk factors that predict CVD events fail to account for the excess CVD mortality found in T2DM patients. A number of studies have identified abnormalities of arterial function in diabetes patients [4-7], and it is now recognized that aortic stiffness, measured by pulse wave velocity (PWV), is highly predictive of cardiovascular and all-cause mortality in subjects with type 2 diabetes and general population, possibly across all age range [8].

Assessment of arterial stiffness in T2DM patients using pulse wave velocity (PWV) is often confounded by coexistent hypertension and blood pressure variations at the time of measurement. In both diabetes and nondiabetes subjects, PWV is strongly associated with age and blood pressure (BP) [4]. However, in sub-Saharan African population, contrary to Caucasians, BP accounts for higher variation of PWV than chronological age [9]. Cardioankle vascular index (CAVI) is a measure of arterial stiffness, reported to be less dependent on $\mathrm{BP}[10]$ and computed using two stiffness indices: $\beta$-stiffness and Bramwell-Hill's formula [11]. The high prevalence of hypertension in T2DM patients makes the contribution of diabetes per se to arterial stiffness difficult to ascertain. In this study, we compared the levels of arterial stiffness in nonhypertensive, nonobese T2DM patients to age- and gendermatched nondiabetes controls. We hypothesize that, compared to age- and gender-match controls, nonhypertensive, nonobese T2DM patients would have higher levels of arterial stiffness. 


\section{Methods}

2.1. Design and Subjects. The study was conducted at the National Diabetes Management and Research Centre, Korle$\mathrm{Bu}$ Teaching Hospital, Accra, Ghana. A total of 166 nonhypertensive, nonobese volunteers, comprising 96 T2DM patients and age- and gender-matched 86 nondiabetes controls within the ages of 35-75 years, were recruited for the study. T2DM was assessed clinically; the patients were diagnosed with diabetes after 30 years of age and treated initially with lifestyle management or oral hypoglycaemic drugs for at least 2 years. T2DM patients were selected by systematic sampling as every 4 th consenting patient visiting the clinic. Based on the gender and age decade of T2DM patients, nondiabetes controls were randomly recruited from the surrounding communities into the study. All the nondiabetes volunteers were screened using fasting plasma glucose (FPG) and 2-hour post-75 g glucose load plasma glucose ( $2 \mathrm{~h}$ PPG) to confirm their nondiabetes status. In all, 95 nondiabetes, nonobese volunteers with no history of hypertension were enrolled into the study. However, 9 participants were excluded from analysis; 6 had impaired fasting glucose and 3 were impaired glucose tolerant (too few to be analysed!). Individuals with foot ulcers, established CVDs, BMI $\geq 30 \mathrm{~kg} / \mathrm{m}^{2}$, history of hypertension treatment, and/or brachial blood pressure $>140 / 90 \mathrm{mmHg}$ were excluded from the study. Ethical approval for this study was given by the University of Ghana Medical School Ethical and Protocol Review Committee (Protocol ID number MSEt/M.2, P.4.10/2012-2013).

2.2. Anthropometric Measurements. Using standard protocols [12], body weight was determined twice using a homologated electronic scale (Seca 770, Hamburg, Germany) following due calibration (precision $\pm 0.1 \mathrm{~kg}$ ), with the patient wearing light clothing and shoes removed. Height was also measured with a portable system (Seca 222, Hamburg, Germany) with the patient shoeless in the upright position. Body mass index (BMI) was calculated as weight $(\mathrm{kg})$ divided by height squared $\left(\mathrm{m}^{2}\right)$. Waist circumference was measured with nonelastic tape measure at the upper border of the iliac crest, parallel to the floor without compressing the skin. Body composition monitor (BF-508, Omron Healthcare, Inc., Vernon Hills, IL, USA) was used to assess percentage body.

2.3. Biochemical Analysis. Blood samples were drawn in the morning, after 8-12 hours of overnight fasting, into plain vacuum tubes to measure plasma lipids and fluoride oxalate tubes for glucose levels. FPG, 2 h PPG, total cholesterol (TC), high-density lipoprotein (HDL) cholesterol, and triglyceride (TG) levels were analysed by colorimetric enzymatic assays using BS 120 chemical autoanalyzer (Mindray, China) and commercial reagents (Randox Laboratory Reagents, UK). Low-density lipoprotein cholesterol levels were calculated using Friedewald's formula [13]. HbAlc was assayed using affinity chromatography on PDQ Plus HPLC autoanalyzer (Primus Diagnostics, Trinity Biotech, Ireland). All analyses were performed at the Diabetes Research and Chronic Disease Reference Laboratory.
2.4. TensioMed Arteriograph Measurements. Arteriograph (TensioMed Kft., Hungary) was used to measure aortic pressure indices, aortic PWV (PWVao), and aortic augmentation index (AIx), with the subject lying supine for at least 10 minutes in a temperature controlled room $\left(22 \pm 2^{\circ} \mathrm{C}\right)$. The Arteriograph cuff was applied on the right arm over the brachial artery to detect arterial wall oscillations in the upper arm using the "stop-flow" principle previously described [14]. To determine aortic PWV, the Arteriograph uses the physiological behaviour of the wave reflection; the ejected direct (first systolic) pulse wave is reflected back mostly from the aortic bifurcation. The device measures the time interval between the peaks of the direct (first) and reflected (late) systolic wave (return time). For both the invasive and noninvasive aortic PWV computations, the aortic length is measured as distance from sternal notch (jugulum) to the upper edge of the pubic bone (symphysis). Stiffer arteries are less elastic and transmit pulse waves faster, reflected earlier at the abdominal aortic bifurcation, resulting in decreased pulse return time and, hence, higher PWV $[15,16]$. To avoid overestimation of aortic path length by body surface contortions, a specialized body caliper was used to measure jugulum-symphysis distance.

PWVao was calculated by using the formula:

$$
\text { PWVao }(\mathrm{m} / \mathrm{s})=\frac{2 \cdot(\text { jugulum-symphysis distance })}{\text { Return time }} \text {. }
$$

Augmentation index (AIx) is computed using the following algorithm:

$$
\mathrm{AIx}=\frac{P_{2}-P_{1}}{\mathrm{PP}} \times 100,
$$

where $P_{1}$ is the amplitude of the first (direct) wave, $P_{2}$ is the amplitude of the late (reflected) systolic wave, and PP is the pulse pressure.

2.5. Vasera Measurements. CAVI and heart-ankle (ha) PWV were measured using the Vasera $1500 \mathrm{~N}$ (Fukuda-Denshi, Japan) with the participant resting supine for at least 10 minutes before the measurement. Electrocardiogram electrodes were placed on both wrists, a microphone for detecting heart sounds was placed on the sternum, and cuffs were wrapped around the upper arms and the ankles. CAVI values were computed automatically. Briefly, CAVI corresponds to the stiffness parameter $\beta$, calculated from values of haPWV and $\mathrm{BP}$ as follows:

$$
\beta=\left(\frac{2 \rho}{\Delta P}\right) \cdot\left[\ln \left(\frac{P_{s}}{P_{d}}\right)\right] \cdot \mathrm{PWV}^{2},
$$

where $\rho$ indicates blood density; $\Delta P$ pulse pressure; ln natural $\log ; P_{s}$ systolic BP; and $P_{d}$ diastolic BP $[11,17]$.

CAVI and Arteriograph measurements were performed in random order using a digital algorithm.

2.6. Statistical Analysis. Continuous data were analysed with the Shapiro-Wilk test to determine their distribution. Skewed data were logarithmically transformed. The data were 


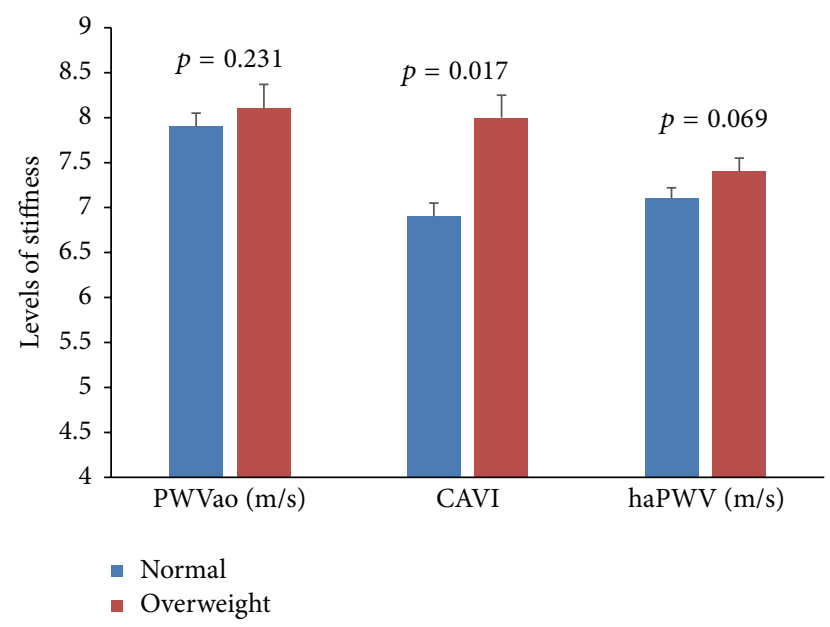

FIGURE 1: Comparison of arterial stiffness indices between normal and overweight participants.

presented as mean \pm standard deviation and analysed by Student's $t$-test. Categorical data were presented as counts (percentages) analysed by the $\chi^{2}$ test. Multiple regression analysis was performed with PWVao and CAVI, as well as haPWV and AIx, as the dependent variable, and the following parameters were forced into the model as covariates: diabetes status, age, gender, duration of diabetes (for T2DM patients group), BMI, height, previous smoking status, alcohol intake, systolic $\mathrm{BP}$, heart rate, $\mathrm{HbAlc}$, total cholesterol, triglycerides, and HDL cholesterol. $p$ values $<0.05$ were considered statistically significant.

\section{Results}

T2DM patients and nondiabetes controls were similar in age, gender distribution, lifestyle (alcohol and previous smoking status), and anthropometric indices. Mean values of AIx and peripheral and central BP indices measured by the Arteriograph were similar between T2DM patients and nondiabetes controls. However, diastolic and pulse BPs measured with Vasera were higher in nondiabetes controls than T2DM patient. Compared to nondiabetes controls, T2DM patients had higher PWVao and CAVI (Table 1). When the study participants were categorised based on BMI, overweight participants (BMI $\left.=25-30 \mathrm{~kg} / \mathrm{m}^{2}, n=94\right)$ had higher CAVI but similar PWVao and haPWV, when compared to normal participants (BMI $\leq 24.9, n=72$; Figure 1). Also, based on BP, prehypertensive ( $\mathrm{BP}=130-139 \mathrm{mmHg}, n=78)$ participants had higher PWVao than nonhypertensive participants $(\mathrm{BP}<$ $130 \mathrm{mmHg}, n=88$; Figure 2).

In correlational analysis, PWVao increases with increasing age $(r=0.33 ; p=0.005)$, body fat $(r=0.26 ; p=0.028)$, brachial systolic pressure $(r=0.25 ; p=0.034)$, and heart rate $(r=0.28 ; p=0.018)$. No association was found between PWVao and duration of diabetes $(r=0.23 ; p=0.055)$, BMI $(r=0.13 ; p=0.272)$, and waist circumference $(r=0.21$; $p=0.086)$. CAVI was found to be positively associated with age $(r=0.64 ; p<0.001)$ and duration of diabetes $(r=0.24$;

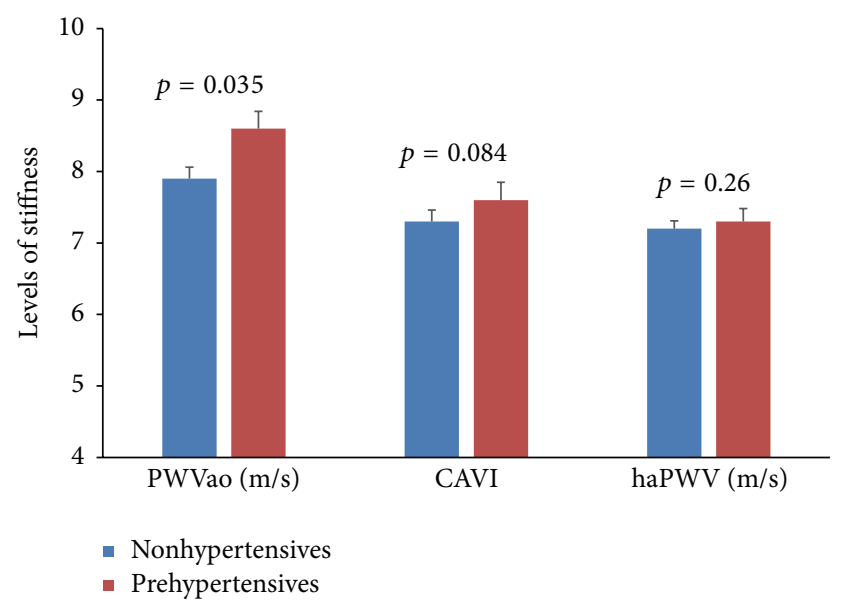

Figure 2: Comparison of arterial stiffness indices between nonhypertensive and prehypertensive participants.

$p=0.041)$ but negatively associated with BMI $(r=-0.26$, $p=0.025)$. CAVI did not show any significant association with the components of brachial blood pressure parameters.

In the multiple regression analysis, determinants of PWVao in the entire study population were diabetes status, age, gender, systolic BP, and previous smoking status; in T2DM patients, they were age, duration of diabetes, gender, systolic BP, alcohol intake, and previous smoking status; in nondiabetes controls, they were age and gender. The determinants of CAVI in entire study population were diabetes status, age, BMI, heart rate, HbAlc, total cholesterol, and HDL cholesterol; in T2DM patients, they were age, duration of diabetes, and total cholesterol; in nondiabetes controls, they were age, WHR, systolic BP, heart rate, HDL cholesterol, and previous smoking status (Table 2). Significant predictors of haPWV in the entire study population were age, gender, BMI, WHR, heart rate, HbAlc, total cholesterol, HDL cholesterol, and alcohol intake; in T2DM patients, they were age, duration of diabetes, gender, WHR, systolic BP, heart rate, HbAlc, and alcohol intake; in nondiabetes controls, they were age, HbAlc, total cholesterol, HDL cholesterol, and alcohol intake. Significant determinants for haPWV in the entire study population were age, gender, BMI, WHR, heart rate, HbAlc, total cholesterol, HDL cholesterol, and alcohol intake; in T2DM patients, they were age, duration of diabetes, gender, WHR, systolic BP, heart rate, $\mathrm{HbAlc}$, and alcohol intake; and in nondiabetes controls, they were age, HbAlc, total cholesterol, HDL cholesterol, and alcohol intake. Significant predictors of AIx in the entire study population were diabetes status, age, gender, body height, systolic BP, heart rate, and $\mathrm{HbAlc}$; in the T2DM patients, they were body height, systolic BP, heart rate, HbAlc, and HDL cholesterol; and in nondiabetes controls, they were age, WHR, body height, HDL cholesterol, and alcohol intake (Table 3).

\section{Discussion}

This study provides data on arterial stiffness in nonhypertensive, nonobese indigenous black Africans with T2DM. 
TABLE 1: Clinical characteristics of study subjects.

\begin{tabular}{|c|c|c|c|}
\hline & $\begin{array}{c}\text { T2DM } \\
\text { patients } \\
(n=96)\end{array}$ & $\begin{array}{l}\text { Controls } \\
(n=70)\end{array}$ & $p$ \\
\hline Age & $51.5 \pm 11.7$ & $50.6 \pm 11.1$ & 0.733 \\
\hline Gender (males/females) & $40 / 56$ & $30 / 40$ & 0.234 \\
\hline Alcohol intake (\%) & 18.2 & 22.1 & 0.078 \\
\hline Previous smokers (\%) & 14.3 & 7.8 & 0.428 \\
\hline Duration of diabetes (years) & $2.6 \pm 1.8$ & - & - \\
\hline$F P G(\mathrm{mmol} / \mathrm{L})$ & $8.4 \pm 3$ & $5 \pm 1$ & $<0.001$ \\
\hline 2 h PPG (mmol/L) & - & $6.2 \pm 2.2$ & - \\
\hline HbAlc (\%) & $8.3 \pm 1.4$ & $5.2 \pm 0.9$ & $<0.001$ \\
\hline Total cholesterol $(\mathrm{mmol} / \mathrm{L})$ & $4.1 \pm 4.2$ & $5.3 \pm 1.4$ & $<0.001$ \\
\hline $\begin{array}{l}\text { Fasting triglycerides } \\
(\mathrm{mmol} / \mathrm{L})\end{array}$ & $1 \pm 0.5$ & $1.1 \pm 0.5$ & 0.310 \\
\hline $\mathrm{HDL}(\mathrm{mmol} / \mathrm{L})$ & $0.8 \pm 0.7$ & $0.8 \pm 0.5$ & 0.793 \\
\hline$L D L(m m o l / L)$ & $4.1 \pm 1.3$ & $2.8 \pm 1.3$ & $<0.001$ \\
\hline BMI $\left(\mathrm{kg} / \mathrm{m}^{2}\right)$ & $26.5 \pm 4.4$ & $28.5 \pm 5.3$ & 0.085 \\
\hline Body fat (\%) & $30.4 \pm 10.1$ & $33.3 \pm 13.7$ & 0.305 \\
\hline Visceral fat (\%) & $11.1 \pm 5.1$ & $9.9 \pm 3.1$ & 0.165 \\
\hline Waist circumference $(\mathrm{cm})$ & $93.9 \pm 10.3$ & $93.5 \pm 17.5$ & 0.897 \\
\hline Waist-hip ratio & $0.91 \pm 0.07$ & $0.92 \pm 0.19$ & 0.797 \\
\hline \multicolumn{4}{|l|}{$\begin{array}{l}\text { Arteriograph } \\
\text { measurements }\end{array}$} \\
\hline$P W \operatorname{Vao}(\mathrm{m} / \mathrm{s})$ & $8.3 \pm 1$ & $7.8 \pm 1.3$ & 0.004 \\
\hline $\begin{array}{l}\text { Aortic systolic BP } \\
(\mathrm{mmHg})\end{array}$ & $116 \pm 12$ & $119 \pm 11$ & 0.195 \\
\hline $\begin{array}{l}\text { Aortic pulse BP } \\
(\mathrm{mmHg})\end{array}$ & $39 \pm 13$ & $43 \pm 14$ & 0.201 \\
\hline Augmentation index (\%) & $20 \pm 12$ & $25 \pm 13$ & 0.138 \\
\hline Systolic BP (mmHg) & $124 \pm 9$ & $124 \pm 10$ & 0.748 \\
\hline Diastolic BP (mmHg) & $74 \pm 7$ & $74 \pm 9$ & 0.977 \\
\hline Pulse BP (mmHg) & $50 \pm 7$ & $50 \pm 8$ & 0.640 \\
\hline Mean BP (mmHg) & $116 \pm 10$ & $115 \pm 11$ & 0.939 \\
\hline Heart rate (bpm) & $74 \pm 10$ & $65 \pm 11$ & 0.001 \\
\hline \multicolumn{4}{|l|}{ Vasera measurements } \\
\hline Systolic BP & $130 \pm 11$ & $133 \pm 32$ & 0.613 \\
\hline Diastolic BP & $82 \pm 8$ & $88 \pm 12$ & 0.039 \\
\hline Pulse BP & $48 \pm 9$ & $50 \pm 12$ & 0.04 \\
\hline Mean BP & $98 \pm 8$ & $104 \pm 14$ & 0.402 \\
\hline Heart rate & $73 \pm 10$ & $65 \pm 12$ & 0.001 \\
\hline CAVI & $7.9 \pm 1.2$ & $6.9 \pm 0.7$ & 0.021 \\
\hline haPWV (m/s) & $7.4 \pm 0.8$ & $7 \pm 0.8$ & 0.263 \\
\hline
\end{tabular}

BMI: body mass index; BP: blood pressure; HR: heart rate; PWVao: aortic pulse wave velocity; AIx: augmentation index; CAVI: cardioankle vascular index; haPWV: heart-ankle PWV.

In this gender and age matched cohort of comparable anthropometric, brachial, and aortic BP indices, we observed increased PWVao and CAVI in T2DM patients compared to nondiabetes controls. The differences in PWVao and CAVI between T2DM patients and nondiabetes controls persisted
TABLE 2: Multiple regression analysis between patients' characteristics versus PWVao and CAVI.

\begin{tabular}{|c|c|c|c|c|}
\hline & \multicolumn{2}{|c|}{ PWVao } & \multicolumn{2}{|c|}{ CAVI } \\
\hline & $\beta$ & $p$ & $\beta$ & $p$ \\
\hline \multicolumn{5}{|l|}{ All subjects } \\
\hline Diabetes status & 0.22 & 0.02 & 0.21 & 0.029 \\
\hline Age & 0.36 & $<0.001$ & 0.38 & $<0.001$ \\
\hline Gender & 0.48 & $<0.001$ & 0.04 & 0.692 \\
\hline $\log \mathrm{BMI}$ & 0.13 & 0.185 & 0.20 & 0.033 \\
\hline $\log \mathrm{WHR}$ & 0.06 & 0.538 & 0.17 & 0.067 \\
\hline log height & 0.16 & 0.092 & 0.05 & 0.577 \\
\hline log systolic BP & 0.21 & 0.005 & -0.08 & 0.309 \\
\hline log heart rate & 0.05 & 0.549 & 0.18 & 0.026 \\
\hline Previous smoking & 0.25 & 0.001 & 0.20 & 0.008 \\
\hline Alcohol intake & 0.01 & 0.894 & 0.02 & 0.759 \\
\hline $\mathrm{HbAlc}$ & 0.01 & 0.922 & 0.24 & 0.007 \\
\hline log total cholesterol & -0.04 & 0.659 & 0.20 & 0.014 \\
\hline log triglycerides & 0.01 & 0.985 & 0.03 & 0.76 \\
\hline $\log \mathrm{HDL}$ & 0.01 & 0.974 & -0.19 & 0.014 \\
\hline \multicolumn{5}{|l|}{ T2DM patients } \\
\hline Age & 0.25 & 0.024 & 2.82 & 0.006 \\
\hline Diabetes duration & 0.27 & 0.01 & 4.29 & $<0.001$ \\
\hline Gender & 0.37 & 0.006 & -1.46 & 0.148 \\
\hline $\log$ BMI & 0.16 & 0.216 & 0.31 & 0.759 \\
\hline $\log \mathrm{WHR}$ & 0.06 & 0.62 & 1.16 & 0.251 \\
\hline log height & -0.01 & 0.947 & -0.84 & 0.404 \\
\hline log systolic BP & 0.34 & 0.003 & 1.37 & 0.176 \\
\hline log heart rate & 0.04 & 0.7 & 1.52 & 0.134 \\
\hline Previous smoking & 0.23 & 0.027 & 0.66 & 0.512 \\
\hline Alcohol intake & 0.20 & 0.043 & 1.44 & 0.155 \\
\hline $\mathrm{HbAlc}$ & -0.10 & 0.424 & 1.92 & 0.058 \\
\hline log total cholesterol & -0.01 & 0.906 & 3.15 & 0.002 \\
\hline log triglycerides & -0.02 & 0.888 & -0.74 & 0.464 \\
\hline $\log \mathrm{HDL}$ & 0.01 & 0.902 & 1.48 & 0.144 \\
\hline \multicolumn{5}{|l|}{ Controls } \\
\hline Age & 0.42 & 0.012 & 2.98 & 0.005 \\
\hline Gender & 0.74 & 0.006 & 0.12 & 0.906 \\
\hline $\log \mathrm{BMI}$ & 0.37 & 0.099 & 1.70 & 0.098 \\
\hline $\log$ WHR & 0.16 & 0.423 & 2.50 & 0.017 \\
\hline log height & 0.34 & 0.074 & 0.92 & 0.363 \\
\hline $\log$ systolic BP & 0.03 & 0.886 & 2.60 & 0.013 \\
\hline log heart rate & 0.28 & 0.217 & 2.15 & 0.038 \\
\hline Previous smoking & 0.19 & 0.21 & 4.10 & $<\mathbf{0 . 0 0 1}$ \\
\hline Alcohol intake & -0.16 & 0.295 & 0.57 & 0.575 \\
\hline HbAlc & 0.30 & 0.109 & 1.18 & 0.244 \\
\hline log total cholesterol & 0.08 & 0.625 & 1.30 & 0.201 \\
\hline log triglycerides & -0.11 & 0.591 & 1.05 & 0.302 \\
\hline $\log \mathrm{HDL}$ & -0.08 & 0.59 & -1.43 & 0.001 \\
\hline
\end{tabular}

after multiple adjustments of various risk factors in regression models. The major finding of this study is that T2DM patients have increased stiffness in the arterial wall in the absence of systemic hypertension. 
TABLE 3: Multiple regression analysis between patients' characteristics versus haPWV and augmentation index.

\begin{tabular}{|c|c|c|c|c|}
\hline & \multicolumn{2}{|c|}{ haPWV } & \multicolumn{2}{|c|}{ AIx } \\
\hline & $\beta$ & $p$ & $\beta$ & $p$ \\
\hline \multicolumn{5}{|l|}{ All subjects } \\
\hline Diabetes status & -0.11 & 0.246 & 0.21 & 0.037 \\
\hline Age & 0.42 & $<0.001$ & 0.14 & 0.018 \\
\hline Gender & -0.22 & 0.03 & 0.20 & 0.017 \\
\hline $\log \mathrm{BMI}$ & 0.29 & 0.003 & 0.01 & 0.94 \\
\hline $\log$ WHR & 0.19 & 0.044 & -0.01 & 0.911 \\
\hline log height & -0.09 & 0.315 & -0.44 & $<0.001$ \\
\hline log systolic BP & 0.09 & 0.217 & 0.14 & 0.018 \\
\hline log heart rate & 0.20 & 0.014 & -0.51 & $<0.001$ \\
\hline Previous smoking & 0.14 & 0.059 & -0.03 & 0.581 \\
\hline Alcohol intake & 0.27 & $<0.001$ & 0.04 & 0.439 \\
\hline $\mathrm{HbAlc}$ & 0.26 & 0.004 & 0.16 & 0.026 \\
\hline log total cholesterol & 0.17 & 0.039 & 0.07 & 0.282 \\
\hline log triglycerides & 0.16 & 0.057 & 0.04 & 0.504 \\
\hline $\log \mathrm{HDL}$ & -0.28 & $<0.001$ & 0.04 & 0.469 \\
\hline \multicolumn{5}{|l|}{ T2DM patients } \\
\hline Age & 0.26 & 0.002 & 0.03 & 0.717 \\
\hline Diabetes duration & 0.45 & $<0.001$ & -0.02 & 0.787 \\
\hline Gender & -0.25 & 0.02 & 0.12 & 0.252 \\
\hline BMI & 0.12 & 0.274 & 0.05 & 0.609 \\
\hline WHR & 0.28 & 0.004 & -0.01 & 0.909 \\
\hline Height & -0.16 & 0.092 & -0.5 & $<0.001$ \\
\hline Systolic BP & 0.41 & $<0.001$ & 0.2 & 0.031 \\
\hline Heart rate & 0.17 & 0.037 & -0.61 & $<0.001$ \\
\hline Previous smoking & 0.11 & 0.191 & -0.05 & 0.555 \\
\hline Alcohol intake & 0.17 & 0.026 & 0.09 & 0.262 \\
\hline HbAlc & 0.2 & 0.017 & 0.29 & 0.001 \\
\hline log total cholesterol & 0.12 & 0.153 & 0.11 & 0.212 \\
\hline log triglycerides & 0.04 & 0.71 & 0.08 & 0.364 \\
\hline $\log \mathrm{HDL}$ & 0.16 & 0.064 & 0.17 & 0.04 \\
\hline \multicolumn{5}{|l|}{ Controls } \\
\hline Age & 0.29 & 0.007 & 0.46 & $<0.001$ \\
\hline Gender & -0.09 & 0.603 & 0.17 & 0.304 \\
\hline BMI & 0.31 & 0.052 & 0.10 & 0.453 \\
\hline WHR & 0.24 & 0.111 & 0.27 & 0.037 \\
\hline Height & 0.06 & 0.623 & -0.58 & $<0.001$ \\
\hline Systolic BP & -0.12 & 0.231 & -0.05 & 0.678 \\
\hline Heart rate & 0.01 & 0.93 & -0.01 & 0.936 \\
\hline Previous smoking & -0.06 & 0.622 & -0.13 & 0.158 \\
\hline Alcohol intake & 0.36 & 0.001 & -0.19 & 0.044 \\
\hline HbAlc & 0.30 & 0.009 & 0.14 & 0.242 \\
\hline log total cholesterol & 0.28 & 0.007 & 0.18 & 0.077 \\
\hline log triglycerides & 0.01 & 0.996 & -0.02 & 0.846 \\
\hline $\log \mathrm{HDL}$ & -0.35 & 0.003 & -0.20 & 0.031 \\
\hline
\end{tabular}

Diabetes is recognized as important risk factor for early arterial aging [8]. Previous studies have shown that T2DM stiffens the aorta and carotid, brachial, femoral, and lower-leg arteries $[5,6]$. Our findings are similar to other studies. Compared to healthy controls, arterial stiffness was reported to be higher in T2DM patients in United Kingdom $[4,18]$. In the Hoorn study, T2DM patients had increased arterial stiffness, measured ultrasonically as distensibility and compliance, of both elastic (carotid) and muscular (femoral and brachial) arteries [19]. Tedesco et al. also reported synergistic effect of hypertension and T2DM on arterial stiffness, measured as carotid-femoral PWV [20]. In Brazilian population studies [21], PWV was higher in diabetes patients than nondiabetes control when stratified by hypertension status.

It is well established that increased arterial stiffness is responsible for the earlier wave reflections and changes in pressure contours, leading to the elevation of peripheral and central systolic pressures and pulse pressure [22, 23]. In this study, however, compared to the nondiabetes controls, PWVao and CAVI were elevated in the T2DM subjects without accompanying increase in brachial and aortic BPs. This observation may indicate that, in T2DM, arterial stiffening precedes BP increase. The short mean duration of diabetes may imply that, at early phase of T2DM, aortic stiffness occurs without any appreciable increase in peripheral and central pressure indices. Insulin resistance and hyperglycaemia associated with T2DM may explain the increased arterial wall hypertrophy and fibrosis [24] through generation of advanced glycated end products [25], oxidative radicals [26], and proinflammatory cytokines [27]. These findings might be in agreement with the observation that people with T2DM have a 3- to 6-fold increased risk of CVDs compared to the general population and, also, the failure of traditional cardiovascular risk factors to account for the excess CVD risk in these patients $[9,22]$. Large arterial stiffness has been demonstrated to be a cardiovascular risk factor in diabetes patients and people impaired glucose tolerance [4, 28]. The major determinants of PWV and CAVI in our study population are similar to what has been published in other studies $[4,5,29]$.

In our study, mean AIx was similar among T2DM patients and nondiabetes controls; however, AIx was related to diabetes status after multiple adjustments of several risk factors in the regression model. Other studies have reported that AIx, which was similar between diabetes and nondiabetes subjects, increased in diabetes patients after adjustment of heart rate [29-32]. However, in one study, which included patients with T1DM and T2DM, no changes in AIx between patients and controls were observed after adjustment of heart rate [5]. AIx measures the arterial function, including wall stiffness, the number and location of reflection sites, and the amplitude and timing of the reflected wave. The inverse relationship between body height and AIx supports the previous findings that people with short stature have reduced distance to arterial pressure reflecting sites and this influences the timing and magnitude of arterial wave travel, causing early return to the heart (during systole) and resulting in an increase in AIx [30]. Short stature is independently associated with CVD mortality in longitudinal studies $[33,34]$ and metaanalysis [35].

In this study, novel equipment, the Arteriograph, was used to measure aortic stiffness. The principle of operation 
of the Arteriograph had been thoroughly investigated with invasive and noninvasive methods and has been found to be the measure of the stiffness of the central aorta in diabetes patients [36] and nondiabetes subjects [37]. The simplicity of the Arteriograph, its operator-independence and measurement using a single brachial cuff, makes it conducive for normal clinical care in low resource region like sub-Saharan Africa. However, the findings of this study indicate that PWVao measured by Arteriograph can covary with BP making aortic stiffness susceptible to white collar effect. The Vasera, which measures arterial stiffness using a novel stiffness index, CAVI, was found to be less dependent on blood pressure in this study. CAVI has been shown to be a useful tool to screen persons with moderate to advanced levels of arteriosclerosis. Horinaka et al. [38] reported that CAVI was strongly associated with plaque burden measure by coronary intravascular ultrasound in the left main coronary artery of patients with coronary artery disease. Mineoka et al. [39] also showed that CAVI correlated with coronary artery calcification, implying that CAVI could be an evaluation index for macrovascular complication of diabetes. In this study, CAVI was found to be associated with most of the traditional cardiovascular risk factors, raising the possibility that CAVI might predict cardiovascular outcomes in population of African ancestry. However, further longitudinal studies are required to investigate this claim.

The haPWV, from which CAVI was derived, measures the stiffness in central (descending aorta) and muscular arteries. The findings of this study show that haPWV was associated with most CVD risk factor. Diabetes affects the stiffness of central elastic arteries more drastically than peripheral muscular arteries [6], making measurement of peripheral arterial stiffness alone less informative in diabetes patients. Unlike stiffness in central elastic arteries (heart-femoral PWV), peripheral stiffness, measured as femoral-ankle PWV, was associated with neither ischaemic heart disease [40] nor chronic kidney disease [41] in T2DM patients. haPWV is rarely reported in literature, but its analogous stiffness index, the brachial-ankle PWV (baPWV), has been widely studied. baPWV is associated with CVD risk factors [42], and, in one study, baPWV was found to be better associated with left ventricular mass, diastolic functions, and other indices of arterial functions better than carotid-femoral PWV [43]. This may imply that peripheral arterial stiffness adds more information of central elastic arterial stiffness in predicting arterial function and target-organ damage.

\section{Limitations of the Study}

The study was a case-control design with subjects recruited from a specialized clinical facility and nondiabetes controls were conveniently sampled from the general population. Hence, we cannot infer causality from the data and the conclusion cannot be generalized to the entire Ghanaian population. In addition, humoural biomarkers that underline the pathophysiological mechanisms of arterial stiffness were not assayed. Of particular importance is hypogonadism, assessed as low plasma testosterone levels, which has been associated with cardiovascular risk factors such as obesity, insulin resistance, metabolic syndrome, and high BP; all these conditions are associated with increased arterial stiffness [44]. Testosterone has also been shown to decrease the intrinsic tone of vascular smooth muscle in chemically induced diabetes animal models by downregulating the activity of the RhoA/Rho kinase involved in calcium signalling in vascular smooth muscle cells [45]. This may partially explain the observation in male diabetes patients, in which PWV was inversely associated with plasma testosterone and dehydroepiandrosterone sulphate levels. Indeed, a recent study involving adult men without any CVDs reported that low testosterone was associated with aortic stiffness [46].

\section{Conclusion}

In summary, this study has shown that arterial stiffness, measured as PWVao and CAVI, is elevated in T2DM patients in the absence of obesity and hypertension. This increase in arterial stiffness was not accompanied with significant elevation of central haemodynamic pressure indices. Hence, in nonhypertensive T2DM patients, medication reducing arterial stiffness such as angiotensin conversion enzyme inhibitors, angiotensin receptor inhibitors, and calcium channel blockers may be beneficial [47]. Also, possibility of reducing arterial stiffness by screening and treating hypogonadism in T2DM patients may be investigated in future studies [48].

\section{Abbreviations \\ PWVao: Aortic pulse wave velocity \\ CAVI: Cardioankle vascular index \\ AIx: Aortic augmentation index \\ haPWV: Heart-ankle pulse wave velocity \\ BP: $\quad$ Blood pressure \\ BMI: Body mass index \\ CVDs: Cardiovascular diseases \\ T2DM: Type 2 diabetes mellitus \\ CVDs: Cardiovascular diseases.}

\section{Competing Interests}

The authors declare that they have no competing interests.

\section{Authors' Contributions}

Kwame Yeboah designed the study, collected and cleaned the data, performed the statistical analysis, wrote the manuscript, and takes overall responsibility of the content of the manuscript. Daniel A. Antwi assisted in the preparation and critically reviewed the manuscript. Ben Gyan assisted in the preparation and critically reviewed the manuscript.

\section{Acknowledgments}

The authors thank the staff of National Diabetes Management of Korle-Bu Teaching Hospital and Research Centre and staff of Diabetes Research \& Chronic Disease Reference, Accra, Ghana. The authors' profound appreciation goes to Professor J. Kennedy Cruickshank and Ms. Virginia Govoni 
of King's College, London, and staff of Clinical Pharmacology, St. Thomas Hospital, London, for provision of training and equipment for this study.

\section{References}

[1] N. J. Morrish, S.-L. Wang, L. K. Stevens et al., "Mortality and causes of death in the WHO multinational study of vascular disease in diabetes," Diabetologia, vol. 44, no. 2, pp. S14-S21, 2001.

[2] A. P. Kengne and A. K. Njamnshi, "Cardiovascular risk reduction in diabetes in sub-saharan Africa: what should the priorities be in the absence of global risk evaluation tools?" Clinical Medicine Insights: Cardiology, vol. 2, p. 25, 2008.

[3] K. Yeboah, P. Puplampu, J. Ainuson, J. Akpalu, B. Gyan, and A. G. B. Amoah, "Peripheral artery disease and exertional leg symptoms in diabetes patients in Ghana," BMC Cardiovascular Disorders, vol. 16, no. 1, article 68, 9 pages, 2016.

[4] L. De Angelis, S. C. Millasseau, A. Smith et al., "Sex differences in age-related stiffening of the aorta in subjects with type 2 diabetes," Hypertension, vol. 44, no. 1, pp. 67-71, 2004.

[5] P. S. Lacy, D. G. O’Brien, A. G. Stanley, M. M. Dewar, P. P. R. Swales, and B. Williams, "Increased pulse wave velocity is not associated with elevated augmentation index in patients with diabetes," Journal of Hypertension, vol. 22, no. 10, pp. 1937-1944, 2004.

[6] E. Kimoto, T. Shoji, K. Shinohara et al., "Preferential stiffening of central over peripheral arteries in type 2 diabetes," Diabetes, vol. 52, no. 2, pp. 448-452, 2003.

[7] K. Yeboah, P. Puplampu, E. Yorke, D. A. Antwi, B. Gyan, and A. G. B. Amoah, "Body composition and ankle-brachial index in Ghanaians with asymptomatic peripheral arterial disease in a tertiary hospital," BMC Obesity, vol. 3, no. 1, pp. 1-7, 2016.

[8] K. Cruickshank, L. Riste, S. G. Anderson, J. S. Wright, G. Dunn, and R. G. Gosling, "Aortic pulse-wave velocity and its relationship to mortality in diabetes and glucose intolerance: an integrated index of vascular function?" Circulation, vol. 106, no. 16, pp. 2085-2090, 2002.

[9] A. E. Schutte, H. W. Huisman, R. Schutte et al., "Arterial stiffness profiles: investigating various sections of the arterial tree of African and Caucasian people," Clinical and Experimental Hypertension, vol. 33, no. 8, pp. 511-517, 2011.

[10] K. Shirai, M. Song, J. Suzuki et al., "Contradictory effects of $\beta 1-$ and $\alpha 1$ - aderenergic receptor blockers on cardio-ankle vascular stiffness Index (CAVI) - CAVI is independent of blood pressure," Journal of Atherosclerosis and Thrombosis, vol. 18, no. 1, pp. 49-55, 2011.

[11] C.-K. Sun, "Cardio-ankle vascular index (CAVI) as an indicator of arterial stiffness," Integrated Blood Pressure Control, vol. 6, pp. 27-38, 2013.

[12] World Health Organization, Waist Circumference and WaistHip Ratio: Report of a WHO Expert Consultation, WHO Document Production Services, Geneva, Switzerland, 2011.

[13] W. T. Friedewald, R. I. Levy, and D. S. Fredrickson, "Estimation of the concentration of low-density lipoprotein cholesterol in plasma, without use of the preparative ultracentrifuge," Clinical Chemistry, vol. 18, no. 6, pp. 499-502, 1972.

[14] I. G. Horváth, Á. Németh, Z. Lenkey et al., "Invasive validation of a new oscillometric device (Arteriograph) for measuring augmentation index, central blood pressure and aortic pulse wave velocity," Journal of Hypertension, vol. 28, no. 10, pp. 20682075, 2010.
[15] J. Sugawara, K. Hayashi, T. Yokoi, and H. Tanaka, "Age-associated elongation of the ascending aorta in adults," JACC: Cardiovascular Imaging, vol. 1, no. 6, pp. 739-748, 2008.

[16] J. Sugawara, K. Hayashi, T. Yokoi, and H. Tanaka, "Carotidfemoral pulse wave velocity: impact of different arterial path length measurements," Artery Research, vol. 4, no. 1, pp. 27-31, 2010.

[17] K. Shirai, J. Utino, A. Saiki et al., "Evaluation of blood pressure control using a new arterial stiffness parameter, cardio-ankle vascular index (CAVI)," Current Hypertension Reviews, vol. 9, no. 1, pp. 66-75, 2013.

[18] P. M. Nilsson, P. Boutouyrie, P. Cunha et al., "Early vascular ageing in translation: from laboratory investigations to clinical applications in cardiovascular prevention," Journal of Hypertension, vol. 31, no. 8, pp. 1517-1526, 2013.

[19] M. T. Schram, R. M. A. Henry, R. A. J. M. van Dijk et al., "Increased central artery stiffness in impaired glucose metabolism and type 2 diabetes: the Hoorn study," Hypertension, vol. 43, no. 2, pp. 176-181, 2004.

[20] M. A. Tedesco, F. Natale, G. Di Salvo, S. Caputo, M. Capasso, and R. Calabró, "Effects of coexisting hypertension and type II diabetes mellitus on arterial stiffness," Journal of Human Hypertension, vol. 18, no. 7, pp. 469-473, 2004.

[21] R. de Oliveira Alvim, P. C. J. L. Santos, M. M. Musso et al., "Impact of diabetes mellitus on arterial stiffness in a representative sample of an urban Brazilian population," Diabetology \& Metabolic Syndrome, vol. 5, no. 1, article 45, 2013.

[22] B. M. Kaess, J. Rong, M. G. Larson et al., "Aortic stiffness, blood pressure progression, and incident hypertension," The Journal of the American Medical Association, vol. 308, no. 9, pp. 875-881, 2012.

[23] G. F. Mitchell, "Arterial stiffness and wave reflection: biomarkers of cardiovascular risk," Artery Research, vol. 3, no. 2, pp. 56-64, 2009.

[24] C. De Ciuceis, D. Rizzoni, E. Porteri et al., "Effects of insulin on endothelial and contractile function of subcutaneous small resistance arteries of hypertensive and diabetic patients," Journal of Vascular Research, vol. 45, no. 6, pp. 512-520, 2008.

[25] S.-Y. Goh and M. E. Cooper, "The role of advanced glycation end products in progression and complications of diabetes," The Journal of Clinical Endocrinology \& Metabolism, vol. 93, no. 4, pp. 1143-1152, 2008.

[26] F. Giacco and M. Brownlee, "Oxidative stress and diabetic complications," Circulation Research, vol. 107, no. 9, pp. 1058-1070, 2010.

[27] B. Basha, S. M. Samuel, C. R. Triggle, and H. Ding, "Endothelial dysfunction in diabetes mellitus: possible involvement of endoplasmic reticulum stress?" Experimental Diabetes Research, vol. 2012, Article ID 481840, 14 pages, 2012.

[28] W. J. Kim, C.-Y. Park, S. E. Park et al., “The association between regional arterial stiffness and diabetic retinopathy in type 2 diabetes," Atherosclerosis, vol. 225, no. 1, pp. 237-241, 2012.

[29] M. Zhang, Y. Bai, P. Ye et al., "Type 2 diabetes is associated with increased pulse wave velocity measured at different sites of the arterial system but not augmentation index in a Chinese population," Clinical Cardiology, vol. 34, no. 10, pp. 622-627, 2011.

[30] R. E. D. Climie, S. B. Nikolic, P. Otahal, L. J. Keith, and J. E. Sharman, "Augmentation index and arterial stiffness in patients with type 2 diabetes mellitus," Artery Research, vol. 7, no. 3-4, pp. 194-200, 2013. 
[31] M. T. Schram, R. M. A. Henry, R. A. J. M. van Dijk et al., "Increased central artery stiffness in impaired glucose metabolism and type 2 diabetes: the hoorn study," Hypertension, vol. 43, no. 2, pp. 176-181, 2004.

[32] J. A. Scott, J. S. Coombes, J. B. Prins, R. L. Leano, T. H. Marwick, and J. E. Sharman, "Patients with type 2 diabetes have exaggerated brachial and central exercise blood pressure: relation to left ventricular relative wall thickness," American Journal of Hypertension, vol. 21, no. 6, pp. 715-721, 2008.

[33] J. P. Kannam, D. Levy, M. Larson, and P. W. F. Wilson, "Short stature and risk for mortality and cardiovascular disease events. The Framingham Heart Study," Circulation, vol. 90, no. 5, pp. 2241-2247, 1994.

[34] T. Forsén, J. Eriksson, Q. Qiao, M. Tervahauta, A. Nissinen, and J. Tuomilehto, "Short stature and coronary heart disease: a 35year follow-up of the Finnish cohorts of the Seven Countries Study," Journal of Internal Medicine, vol. 248, no. 4, pp. 326-332, 2000.

[35] T. A. Paajanen, N. K. J. Oksala, P. Kuukasjärvi, and P. J. Karhunen, "Short stature is associated with coronary heart disease: a systematic review of the literature and a meta-analysis," European Heart Journal, vol. 31, no. 14, pp. 1802-1809, 2010.

[36] N. B. Rossen, E. Laugesen, C. D. Peters et al., "Invasive validation of arteriograph estimates of central blood pressure in patients with type 2 diabetes," American Journal of Hypertension, vol. 27, no. 5, pp. 674-679, 2014.

[37] I. G. Horváth, Á. Németh, Z. Lenkey et al., "Invasive validation of a new oscillometric device (Arteriograph) for measuring augmentation index, central blood pressure and aortic pulse wave velocity," Journal of Hypertension, vol. 28, no. 10, pp. 20682075, 2010.

[38] S. Horinaka, A. Yabe, H. Yagi et al., "Cardio-ankle vascular index could reflect plaque burden in the coronary artery," Angiology, vol. 62, no. 5, pp. 401-408, 2011.

[39] Y. Mineoka, M. Fukui, M. Tanaka et al., "Relationship between cardio-ankle vascular index (CAVI) and coronary artery calcification (CAC) in patients with type 2 diabetes mellitus," Heart and Vessels, vol. 27, no. 2, pp. 160-165, 2012.

[40] S. Hatsuda, T. Shoji, K. Shinohara et al., "Regional arterial stiffness associated with ischemic heart disease in type 2 diabetes mellitus," Journal of Atherosclerosis and Thrombosis, vol. 13, no. 2, pp. 114-121, 2006.

[41] E. Kimoto, T. Shoji, K. Shinohara et al., "Regional arterial stiffness in patients with type 2 diabetes and chronic kidney disease," Journal of the American Society of Nephrology, vol. 17, no. 8, pp. 2245-2252, 2006.

[42] S. Tsuchikura, T. Shoji, E. Kimoto et al., "Brachial-ankle pulse wave velocity as an index of central arterial stiffness," Journal of Atherosclerosis and Thrombosis, vol. 17, no. 6, pp. 658-665, 2010.

[43] W.-C. Yu, S.-Y. Chuang, Y.-P. Lin, and C.-H. Chen, "Brachialankle vs carotid-femoral pulse wave velocity as a determinant of cardiovascular structure and function," Journal of Human Hypertension, vol. 22, no. 1, pp. 24-31, 2008.

[44] G. Corona, E. Mannucci, G. Forti, and M. Maggi, "Hypogonadism, ED, metabolic syndrome and obesity: a pathological link supporting cardiovascular diseases," International Journal of Andrology, vol. 32, no. 6, pp. 587-598, 2009.

[45] L. Vignozzi, A. Morelli, S. Filippi et al., "Testosterone regulates RhoA/Rho-kinase signaling in two distinct animal models of chemical diabetes," The Journal of Sexual Medicine, vol. 4, no. 3 , pp. 620-632, 2007.
[46] C. Vlachopoulos, N. Ioakeimidis, M. Miner et al., "Testosterone deficiency: a determinant of aortic stiffness in men," Atherosclerosis, vol. 233, no. 1, pp. 278-283, 2014.

[47] A. Adji, M. F. O’Rourke, and M. Namasivayam, "Arterial stiffness, its assessment, prognostic value, and implications for treatment," American Journal of Hypertension, vol. 24, no. 1, pp. 5-17, 2011.

[48] A. Morgentaler, M. M. Miner, M. Caliber, A. T. Guay, M. Khera, and A. M. Traish, "Testosterone therapy and cardiovascular risk: advances and controversies," Mayo Clinic Proceedings, vol. 90, no. 2, pp. 224-251, 2015. 


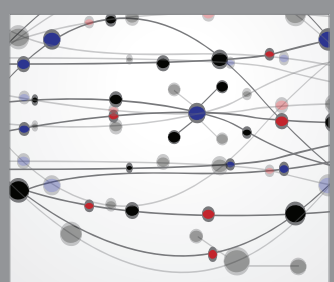

The Scientific World Journal
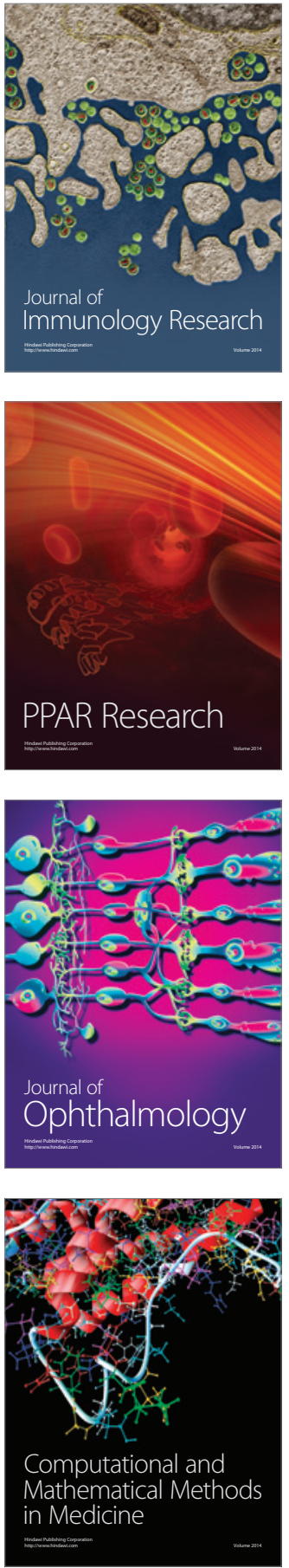

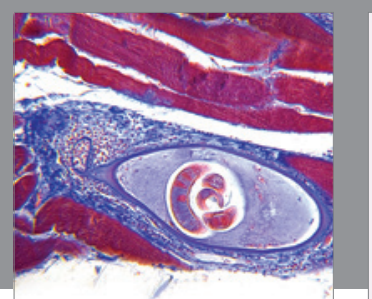

Gastroenterology Research and Practice

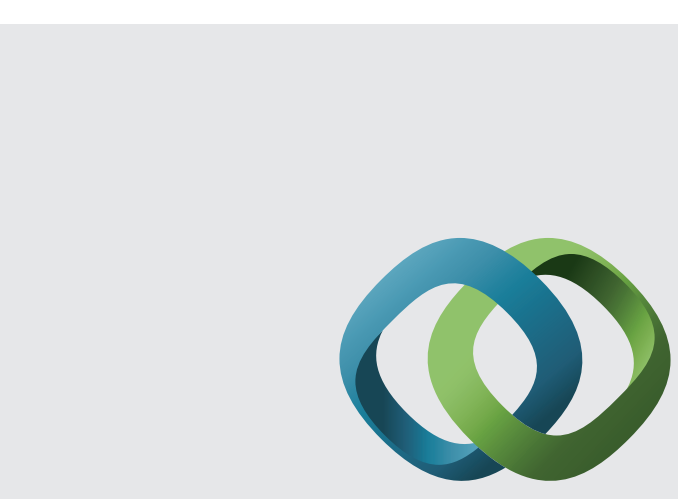

\section{Hindawi}

Submit your manuscripts at

http://www.hindawi.com
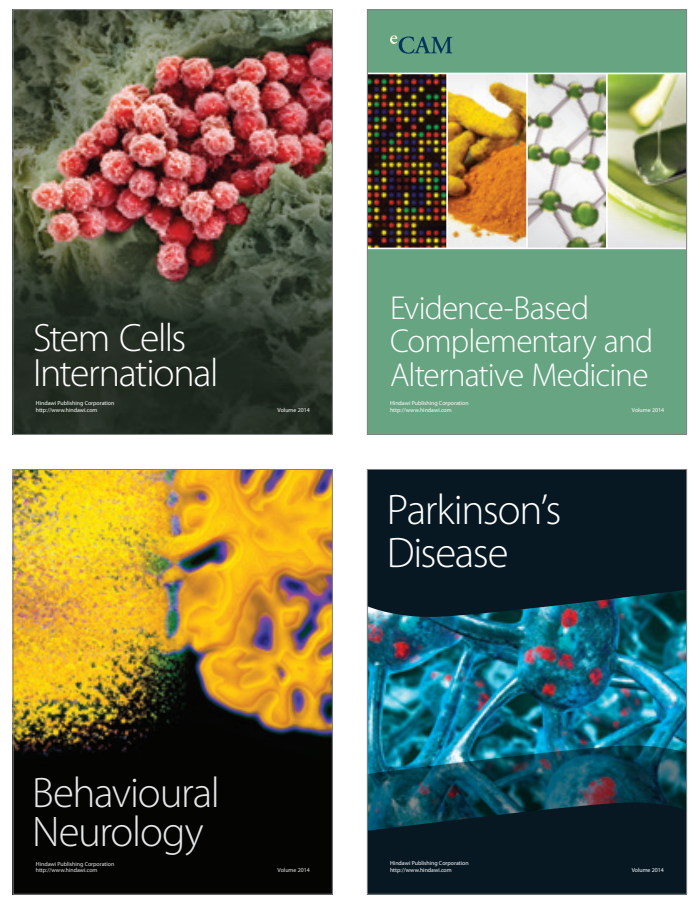
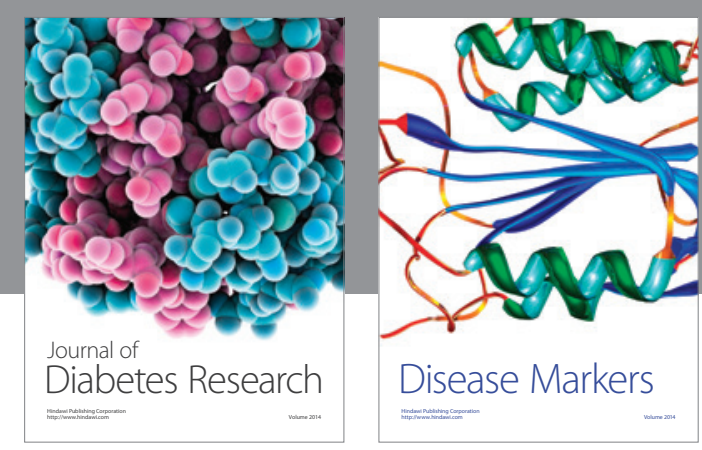

Disease Markers
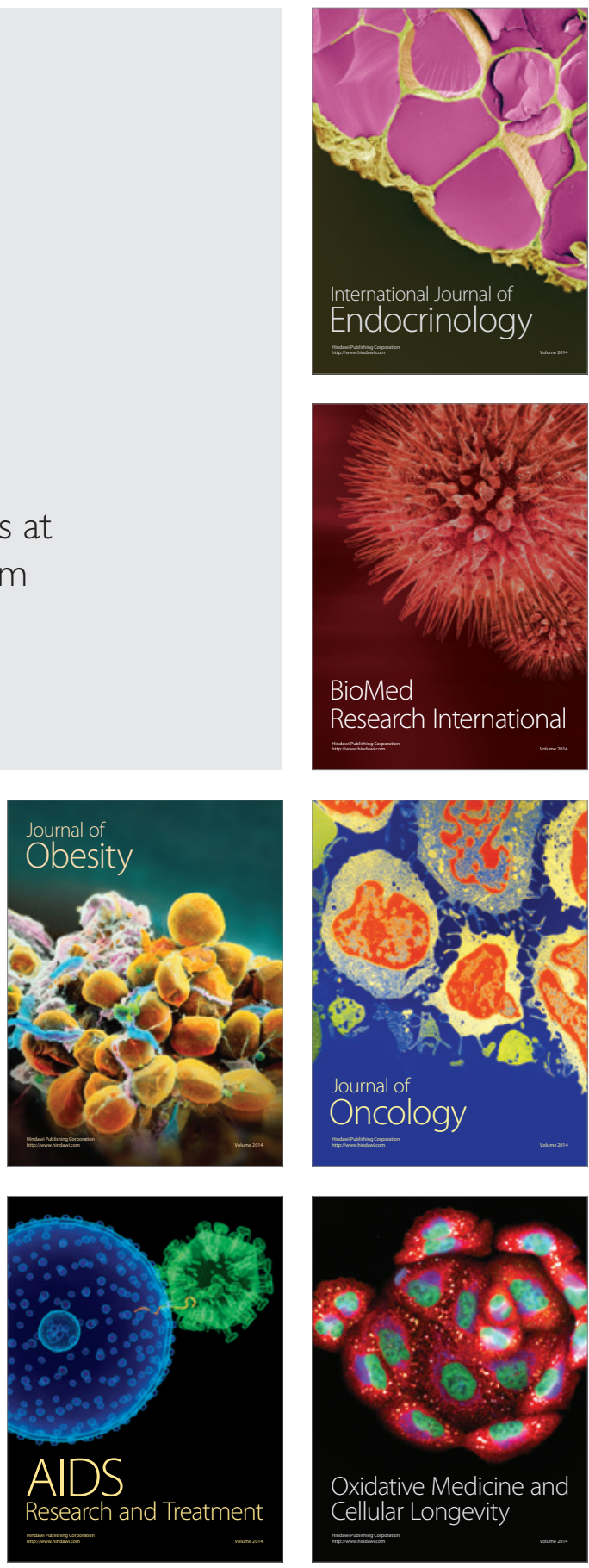